\title{
AVALIAÇÃO COOPERATIVA PARA IDENTIFICAR PROBLEMAS DE USABILIDADE NA INTERFACE DE UMA BASE DE DADOS BIBLIOGRÁFICA TEMÁTICA, A PARTIR DA PERFORMANCE DO USUÁRIO EXPERIENTE
}

\section{COOPERATIVE EVALUATION TO IDENTIFY USABILITY PROBLEMS IN THE INTERFACE OF A THEMATIC BIBLIOGRAPHIC DATABASE, FROM THE EXPERIENCED USER PERFORMANCE}

\author{
Cláudia Souza e Silva ${ }^{1}$, M.Sc \\ cssaar@gmail.com e https://orcid.org/0000-0001-8790-849X \\ André Ribeiro de Oliveira ${ }^{1}$, D.Sc. \\ andre.ribeiro@eng.uerj.br e https://orcid.org/0000-0003-2304-8288
}

${ }^{1}$ Escola Superior de Desenho Industrial, Universidade do Estado do Rio de Janeiro, Rio de Janeiro, Brasil

\begin{abstract}
Design de interação, Experiência do usuário, Avaliação cooperativa, Usabilidade
Este trabalho teve por objetivo avaliar a usabilidade da base de dados bibliográfica disponibilizada por uma das bibliotecas temáticas da Fundação Oswaldo Cruz para consulta ao seu acervo. Pretendeu-se compreender os fatores que tem influência sobre a realização da busca por informação em bases de dados e considerou-se o componente da usabilidade, performance do usuário experiente (EUP), como fator para a escolha do recorte da população, a qual foi composta por bibliotecários atuantes na biblioteca. Como método foi utilizada a avaliação cooperativa, que possui como vantagem a interação direta entre pesquisador e usuário, para identificação dos problemas mais significativos de um sistema. Como resultado, verificou-se que a experiência dos bibliotecários no uso do sistema e o domínio do conhecimento sobre o acervo e o seu tema tiveram impacto sobre o processo de busca, facilitando o uso da base de dados bibliográfica. Ao final foram elencadas considerações dos especialistas para melhoria do sistema.
\end{abstract}

Interaction design, User experience, Cooperative evaluation, Usability

This work aimed to evaluate the usability of the bibliographic database made available by one of the thematic libraries of the Oswaldo Cruz Foundation to consult its collection. It was intended to understand the factors that have an influence on the search for information in databases and the usability component, experienced user performance (EUP), was considered as a factor for choosing the research population, which was composed by librarians working in the library. As a method, cooperative evaluation was used, which has the advantage of direct interaction between researcher and user, to identify the most significant problems of a system. As a result, it was found that the experience of librarians in using the system and their knowledge about the collection and its theme had an impact on the search process, facilitating the use of the bibliographic database. At the end, the expert's considerations for improving the system were listed.

DOI: http://dx.doi.org/10.22570/ergodesignhci.v8i2.1465 


\section{Introdução}

Os acervos bibliográficos se configuram como um tipo de patrimônio cultural e são organizados e disponibilizados para consulta pública através de bibliotecas, entre as quais se encontram as temáticas, que são assim denominadas por abrigarem acervos, com publicações relacionadas a um campo ou tema específico. Para a consulta aos seus acervos, as bibliotecas fornecem duas formas de serviço, pela consulta presencial e pela virtual e ambas contam com o apoio de sistemas de busca informatizados, as bases de dados bibliográficas. Tanto os bibliotecários, quanto os usuários fazem uso das mesmas bases de dados. No serviço de acesso físico há a facilitação da consulta por profissionais especializados, que dão direção para os recursos de informação necessários ao atendimento da demanda feita pelo usuário, na sua temática de busca, como coloca Duarte et al (2015). Já no serviço de acesso virtual, o usuário realiza toda a tarefa de forma autônoma, sem o auxílio de um profissional. De acordo com Ahmed, McKnight e Oppenheim (2004 apud Mesquita et al, 2005), com o advento da web, os usuários finais dos documentos passaram a ter acesso diretamente aos instrumentos de pesquisa, antes manuseados apenas pelos profissionais de informação, que detinham o conhecimento da complexidade das estratégias de pesquisa. Esses sistemas, quando disponibilizados para os usuários finais terem acesso aos acervos sem intermediação, precisam ser menos complexos e não baseados em um conhecimento especializado, para serem úteis aos seus usuários. Neste sentido, sistemas que facilitem o processo de busca da informação, podem auxiliar a realização da tarefa pelos usuários. O primeiro contato dos usuários das bibliotecas com os seus acervos é feito através das bases de dados para procura pelos itens bibliográficos, com o objetivo de obter informações sobre as obras, a sua localização, disponibilidade etc. Quando o usuário enfrenta dificuldades para encontrar a informação, é possível que não obtenha uma resposta plenamente satisfatória para a sua pesquisa, não recupere toda a informação que procura ou até mesmo que desista da busca e opte por mecanismos mais populares de busca da informação, mas que apresentam resultados sem uma filtragem adequada e por vezes não confiáveis.

Segundo colocado por Lancaster (2004 apud Mesquita et al, 2005, p. 2), uma base de dados bibliográfica deve além de ter uma boa cobertura sobre um determinado assunto, possibilitar que os seus itens possam ser recuperados mediante uma estratégia de busca que não seja muito complexa. A compreensão acerca da importância das bibliotecas depende da publicização e uso dos seus acervos, portanto, a facilitação do acesso aos acervos bibliográficos é estratégica para que os tornem conhecidos e utilizados pelos seus públicos. Sendo assim, um dos aspectos fundamentais na facilitação do acesso aos acervos de bibliotecas é a facilidade no uso das suas bases bibliográficas. Como objeto deste estudo sobre a facilidade de uso de uma base de dados bibliográfica, procedeu-se a avaliação da base disponibilizada pela Biblioteca em História das Ciências e da Saúde da Fundação Oswaldo Cruz, para dar acesso ao seu acervo temático.

A facilidade de uso de um sistema é definida como usabilidade por Jordan (1998) e se refere ao quão fácil é a sua utilização pelo usuário e se caracteriza por três variáveis, eficácia, eficiência e satisfação. Considerouse para este estudo, a eficácia como a capacidade do sistema interativo em operacionalizar a busca de registros bibliográficos com a maior capacidade automática de recuperação da informação e como eficiência a capacidade do sistema em exigir o menor esforço por parte do usuário. A variável satisfação, apesar de fazer parte da definição de usabilidade apresentada na ISO 9241:11, tem seu conceito questionado por muitos pesquisadores por ser limitada ao não incluir uma abordagem estética e emocional, segundo Cybis, Betiol e Faust (2010). A satisfação no uso possui estreita relação com o conceito de experiência do usuário e percepção da facilidade de uso. Como o objetivo deste trabalho não se refere a facilidade percebida e sim aos aspectos objetivos no uso do sistema, esta variável não foi abordada neste estudo. Jordan (1998) coloca ainda que a usabilidade possui cinco componentes, dos quais considerou-se para investigação nesta pesquisa, a performance do usuário experiente (EUP), como fator para a escolha do recorte da população, sendo assim selecionados como participantes, usuários especialistas no tema e no acervo da biblioteca e no uso da base de dados bibliográfica. Os outros componentes da usabilidade, guessability e learnability, também relacionados a mudança do nível de desempenho da tarefa a partir da experiência, não serão abordados neste estudo, pois se referem a usuários no uso de um produto pela primeira vez e a usuários que alcançam um nível de competência aceitável a partir da repetição de tarefas. Os dois últimos componentes de usabilidade 
desenvolvidos por Jordan (1998), reutilização e potencial do sistema, são relacionados ao nível de desempenho de tarefas específicas e a quando o usuário retorna após um longo período sem utilizar o sistema. Como o sistema oferece apenas algumas funções já de conhecimento avançado dos bibliotecários e a utilização é de forma constante, estes componentes também não serão abordados. A concentração da investigação quanto à EUP, se mostrou a mais adequada para verificar se isto interfere na busca e no encontro da informação.

De acordo com Cybis, Betiol e Faust (2010, p.16), a usabilidade "depende de um acordo entre as características de sua interface e as características de seus usuários ao buscarem determinados objetivos em determinadas situações de uso". Tomando-se então, a dependência da relação entre a interface e as características dos usuários, descrita por Cybis, Betiol e Faust (2010) para a qualidade da usabilidade e a EUP como um dos componentes da usabilidade apresentados por Jordan (1998), o objetivo deste estudo foi avaliar a usabilidade de uma base de dados bibliográfica, a partir do uso do sistema por um público especialista. O componente de EUP considerou dois aspectos quanto à experiência: a familiaridade com o uso de bases de dados bibliográfica, que fazem parte da experiência profissional e do conhecimento dos bibliotecários na sua área de atuação e o domínio do conhecimento sobre a temática do acervo e da organização do acervo propriamente dito.

Como método para análise, optou-se pela avaliação cooperativa. Nesta técnica, através de uma abordagem qualitativa, os participantes, entrevistados em sessões individuais, interagem com um pesquisador, enquanto executam tarefas em uma interface. Como recorte para a pesquisa foram entrevistados sete bibliotecários, com experiência de atuação entre dois e onze anos na referida biblioteca. Foram previamente estipuladas quatro tarefas, que representam pesquisas usuais no dia a dia dos bibliotecários. Tal estudo justifica-se pela necessidade de identificação de problemas que afetam o encontro da informação e do entendimento de que fatores tem influência sobre a busca, visto que bases de dados bibliográficas são disponibilizadas para consulta autônoma por usuários especialistas e não especialistas. $\mathrm{O}$ experimento realizado com usuários especializados foi proposto pelos mesmos possuírem uma visão privilegiada e holística da operação de busca e recuperação da informação. Quanto à organização, este estudo foi dividido em seis seções. A primeira seção fornece uma visão geral do estudo, com uma breve introdução sobre o objeto de estudo, o objetivo, as variáveis e o componente de análise e o método. Na segunda seção descreve-se o objeto de análise. Na terceira seção apresenta-se o referencial teórico, ancorado na literatura, sobre avaliação cooperativa e usabilidade. A quarta seção se refere ao método utilizado para esta pesquisa, com a definição das etapas e do recorte da população participante do estudo. A quinta seção trata dos resultados obtidos, que foram divididos em descrição e análise das tarefas aplicadas na avaliação, análise quanto ao componente de EUP, considerações dos especialistas acerca de problemas encontrados que tem influência na busca e recuperação das informações e finalmente a avaliação quanto à usabilidade da base de dados bibliográfica, a partir da análise do resultado das tarefas, do componente de usabilidade e das considerações feitas pelos especialistas. A última seção consiste na conclusão do estudo.

\section{A base de dados bibliográfica}

A Biblioteca em História das Ciências e da Saúde faz parte da rede de bibliotecas da Fundação Oswaldo Cruz e utiliza uma base de dados bibliográfica ${ }^{1}$, desenvolvida a partir do aplicativo LILDBI-Web ${ }^{2}$, a qual referencia o acervo da biblioteca temática, que conta com cerca de 76 mil itens, disponíveis para consulta.

\footnotetext{
${ }^{1} \mathrm{http}: / /$ basecoc.coc.fiocruz.br

${ }^{2}$ O LILDBI-Web foi desenvolvido pela Bireme (Centro Latino-Americano e do Caribe de Informação em Ciências da Saúde), que faz parte da OPAS (Organização Pan-Americana da Saúde) e da OMS (Organização Mundial da Saúde). Trata-se de um aplicativo para auxílio ao trabalho de criação e descrição de registros bibliográficos na metodologia LILACS (Literatura Latino-Americana em Ciências da Saúde) e é acessado através da web. Fonte: Disponível em:< http://red.bvsalud.org/lildbi-web/>. Acesso em: 06 jan. 2020. 
As referências bibliográficas disponibilizadas são utilizadas para pesquisa sobre as publicações pertencentes à biblioteca, tanto pelos usuários, quanto pelos bibliotecários. Estes últimos as utilizam para: auxiliar os usuários na solicitação de acesso aos originais depositados na biblioteca física; como parte do processo de tratamento da informação; como instrumento de verificação do acervo; e como parte do processo de elaboração de instrumentos para divulgação do acervo.

$\mathrm{O}$ acesso ao documento físico, tem como primeira etapa a busca pelo registro da sua referência bibliográfica constante na base de dados, a qual fornece informações quanto as obras, como título, autor, entre outras.

A busca é realizada através de dois tipos de formulários. No formulário de busca simplificada (figura 1), é apresentado apenas um campo para preenchimento dos termos de busca, que pesquisa em todos os campos descritivos da obra, como título, autor etc. No formulário para busca avançada (figura 2) são fornecidos três campos para preenchimento, com a opção de uso de operadores booleanos (AND, NOT, AND NOT) a partir do segundo campo, para relacionar os campos de preenchimento dos termos de busca aos campos descritivos das obras. Estes últimos serão aqui tratados como filtros, para distinção dos campos de preenchimento.

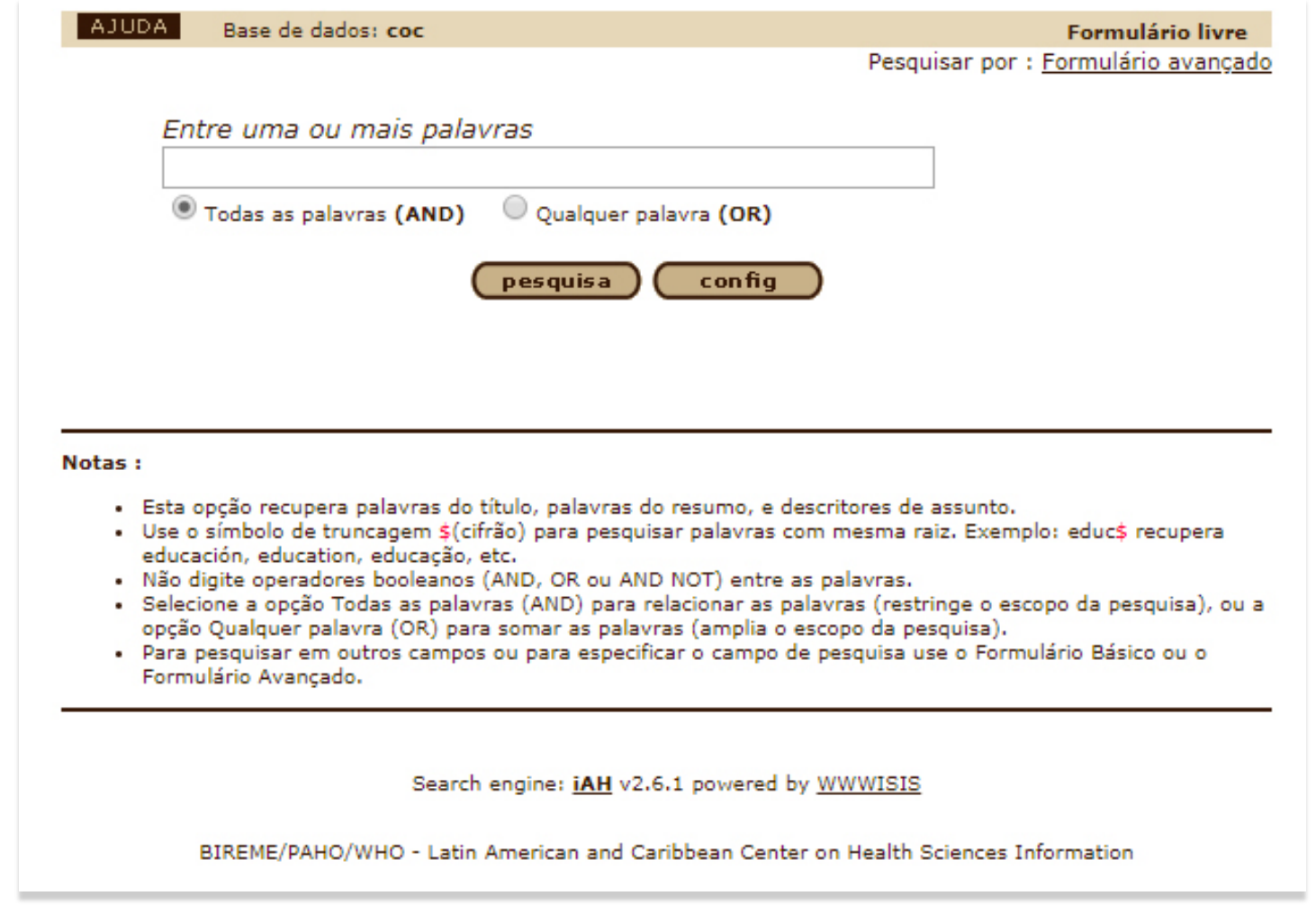

Figura 1: Formulário de busca simples e informações sobre como pesquisar. 
AJUDA Base de dados : coc $\quad$ Formulário avançado

Pesquisar por : Formulário livre

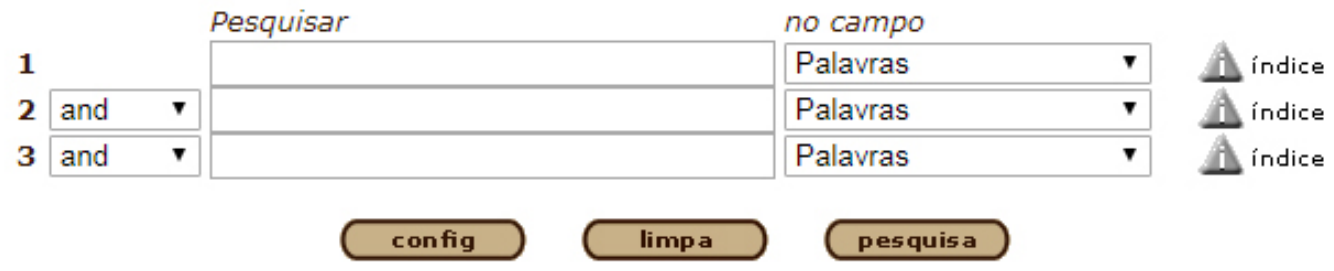

Search engine: $\underline{\text { iAH }}$ v2.6.1 powered by WWWISIS

BIREME/PAHO/WHO - Latin American and Caribbean Center on Health Sciences Information

Figura 2: Formulário de busca avançada, com três campos para combinação de termos com uso de operadores booleanos, campos para filtragem e acesso aos índices de termos.

\section{Referencial teórico}

Dois assuntos foram abordados no referencial teórico: a usabilidade, que é o tema desta pesquisa e o método proposto para viabilização do estudo, a avaliação cooperativa.

Com relação ao primeiro assunto, Jordan (1998) se refere à usabilidade como um tema importante de estudo, principalmente se levarmos em consideração que muitas atividades profissionais envolvem o uso de computadores e os artefatos tecnológicos fazem parte do nosso dia a dia. $\mathrm{O}$ autor define a usabilidade como o quão fácil é o uso de um sistema ou de um produto por um usuário.

Já Nielsen (2003), define a usabilidade como um atributo de qualidade que avalia o quanto as interfaces são fáceis de usar pelos usuários, sendo formada por cinco componentes: facilidade de aprendizagem, eficiência, capacidade de memorização, prevenção a erros e satisfação.

Tanto Jordan (1998), quanto Cybis, Betiol e Faust (2010), se referem à usabilidade como um conjunto de fatores: interface, usuário, objetivo e situação de uso. De acordo com Cybis, Betiol e Faust (2010), "uma mesma interface pode proporcionar interações satisfatórias para usuários experientes e deixar muito a desejar quando utilizada por novatos" (CYBIS; BETIOL; FAUST, 2010, p.16). Esta colocação situa a usabilidade não como uma qualidade intrínseca de um sistema, mas como uma relação de dependência. Um sistema não é fácil ou difícil de forma independente do seu usuário. Jordan (1998) corrobora com essa afirmação colocando que a facilidade ou dificuldade para conclusão de uma tarefa particular pode ser influenciada pela experiência que o usuário já tenha com o sistema e que as características do usuário podem ser indicadores da facilidade ou dificuldade do sistema para este usuário específico. Cybis, Betiol e Faust (2010) acrescentam ainda que as pessoas, com a experiência de uso, ao perceberem novas possibilidades e funcionalidades, desenvolvem estratégias no uso de interfaces, mais variadas do que se pode supor. Essas situações de uso podem ser analisadas, para pesquisa, durante a interação entre usuário e sistema. Segundo Jordan (1998) três variáveis são utilizadas para avaliar a usabilidade: eficácia, eficiência e satisfação. A eficácia se refere ao alcance de um objetivo, tarefa ou meta, que pode ser total ou parcial, a eficiência se refere ao esforço necessário para atingir um objetivo ou meta e a satisfação se refere ao nível de conforto que o usuário sente ao navegar, sendo relacionada a fatores mais subjetivos, de percepção do usuário. De acordo o autor, existem cinco componentes de usabilidade: guessability, learnability, 
performance do usuário experiente (Experienced User Performance - EUP), potencial do sistema e reutilização. Os três primeiros se referem à diferença do nível de desempenho da tarefa, sendo o guessability referente ao uso de um sistema para execução de uma nova tarefa pela primeira vez e o learnability, quanto ao alcance de algum nível de competência com o desempenho de uma tarefa, depois de passadas as dificuldades de uso de uma primeira vez.

Já a performance do usuário experiente (EUP) se refere ao nível de conhecimento adquirido por um usuário. Uma vez que a lógica da operação seja absorvida, a performance se torna estável, de alto nível. A EUP se refere efetivamente ao domínio de conhecimento de um usuário, com relação a tarefa. Este domínio se refere ao conhecimento sobre uma tarefa que não depende do sistema ou da ferramenta que está sendo utilizada para a realização, ou seja, é um conhecimento em um nível superior e mais abrangente do que o conhecimento de uma ferramenta específica. Jordan (1998) cita o uso de softwares complexos e dirigir um carro, por exemplo, como tarefas que independem do conhecimento de uma ferramenta específica, como apenas uma versão do software ou um modelo de carro, porque o domínio do conhecimento se refere à tarefa e não ao instrumento específico.

Os componentes, reutilização e potencial do sistema, se referem, respectivamente, a sistemas de uso não frequente e que possam ter como consequência que o usuário desaprenda o sistema ao voltar a utilizar e a sistemas que ofereçam atalhos ou saltos para realização das tarefas.

O segundo assunto desta seção se refere ao método utilizado para esta pesquisa. De acordo com Nielsen (2003), entre os vários métodos para avaliação da usabilidade, o mais útil e básico é o teste com usuários, composto por três variáveis: usuários representativos dos usuários reais, tarefas representativas e observação do que os usuários fazem, bem como os sucessos e dificuldades com a interface. Para este estudo optou-se pela avaliação cooperativa, que é uma das técnicas para teste da usabilidade de um produto. De acordo com Santa Rosa e Moraes (2012) na avaliação cooperativa, o objetivo é a identificação dos problemas mais significativos do sistema. Com base nesse levantamento são apontados os problemas que necessitam de correção, para melhoria da capacidade do sistema. De acordo com Santos e Freitas (2017, p.66), conforme citado por Ciccarelli, Granja e Renzi, $(2018$, p.5) a aplicação da avaliação cooperativa é indicada para sistemas prontos ou já em uso. Esta colocação tem a corroboração de Santa Rosa e Moraes (2012) ao colocarem que esta técnica deve ser utilizada em produtos já existentes e evitada a sua aplicação em produtos em início de construção, pela falta de requisitos e informações mais consistentes sobre as tarefas possíveis.

Esta técnica pode ser considerada como uma técnica de projeto participativo e possui como vantagem a interação direta entre pesquisador e usuário. Sendo assim, é possível obter um feedback por parte do participante, que pode ser explorado mais a fundo quando necessário, e que possibilita a compreensão da visão do usuário sobre um produto a partir das suas colocações no momento do uso. Segundo Monk et al. (1993 apud Veiga et al, 2013), esta técnica possibilita ao avaliador a obtenção de dados e aspectos que necessitam de alterações para a melhoria do sistema. A avaliação ocorre a partir da interação entre usuário e avaliador, onde o primeiro é incentivado a expor as suas percepções, certezas e dúvidas e o segundo atua como um encorajador do processo e como um observador da interação entre o usuário e o sistema em tarefas pré-estabelecidas. De acordo com Veiga et al (2013, p.7), "o avaliador deixa que o usuário cometa erros e utiliza as perguntas do usuário para obter mais informações sobre problemas em potencial". Isto faz com que o processo de avaliação seja mais dinâmico e possa ocorrer de forma variável entre usuários.

\section{Método da pesquisa}

Esta seção apresenta o método de avaliação cooperativa, baseado nas definições citadas no referencial teórico e nas colocações de Santa Rosa e Moraes (2012) sobre a busca pelos problemas mais significativos que impactam a utilização do sistema e de Santos e Freitas (2017 apud Ciccarelli, Granja e Renzi, 2018) de que a avaliação deve ser conduzida em sistemas já existentes. $O$ método foi estruturado para avaliar a

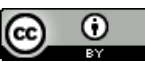


usabilidade de uma base de dados bibliográfica com relação ao seu uso por usuários experientes no sistema e no tema do acervo.

Como objeto de estudo foi analisada a interface da base de dados bibliográfica utilizada pela Biblioteca em História das Ciências e da Saúde, através de uma avaliação cooperativa. No caso desta pesquisa, que tem uma abordagem qualitativa, optou-se por esta técnica por possibilitar ao pesquisador interagir com os usuários durante as tarefas, em um sistema já amplamente conhecido pelos mesmos. A facilidade de acesso aos bibliotecários e a disponibilidade de locais com condições físicas adequadas para a realização das entrevistas foram também fatores determinantes para a escolha do uso desta técnica específica.

Pelo público selecionado ser composto apenas de especialistas, prospectou-se que as informações mais relevantes fossem quanto a verbalização dos problemas encontrados, quanto aos comentários sobre a interface do sistema e o processo de busca, do que quanto aos resultados quantitativos encontrados pelos participantes. As tarefas elaboradas tiveram um caráter aberto, não se limitando a busca de uma publicação ou caminho específico para encontro da informação. Esta opção se deu por dois motivos: o primeiro em decorrência do público selecionado para a pesquisa ser formado por especialistas, portanto uma tarefa de busca simples por uma publicação por título, por exemplo, não traria a complexidade necessária à pesquisa. $\mathrm{O}$ segundo pelo fato da base bibliográfica utilizada para a pesquisa, apresentar apenas os campos de busca e a listagem de resultados, sem um percurso de navegação complexo. Deste modo, o conjunto de tarefas consistiu em encontrar publicações acerca do cientista Carlos Chagas e da Doença de Chagas.

A avaliação cooperativa seguiu as seguintes etapas:

- Recrutamento de sete participantes;

- Preparação da tarefa;

Os temas pesquisados, Carlos Chagas e Doença de Chagas, foram escolhidos por serem assuntos relacionados entre si, já que o cientista, cujo nome completo é Carlos Ribeiro Justiniano das Chagas, foi o descobridor da enfermidade. $\mathrm{O}$ acervo possui obras de homônimos do cientista e apenas as obras sobre o aspecto histórico da doença dizem respeito ao seu criador, o que requer o uso de filtragem da informação, para obtenção de um resultado fidedigno da realidade do acervo pertencente à biblioteca. As tarefas destacadas para este estudo foram:

1. Localizar obras do cientista Carlos Chagas que fazem parte do acervo;

2. Localizar obras sobre o cientista Carlos Chagas que fazem parte do acervo;

3. Localizar obras sobre Doença de Chagas que fazem parte do acervo;

4. Localizar obras, do acervo, que relacionam a Doença de Chagas ao cientista Carlos Chagas.

Para verificação da pertinência das questões e comparação com os resultados encontrados pelos bibliotecários, foram realizadas duas pesquisas prévias para relacionar os registros constantes na base bibliográfica do acervo. A primeira pesquisa, pelo termo Carlos Chagas recuperou 289 registros e a segunda pesquisa, pelo termo Doença de Chagas recuperou 282 registros. Como procedimento para estas buscas foi utilizado o formulário simplificado, que retorna um resultado sem filtragem, pois recupera em todos os campos da base. Fez-se uma verificação dos resultados para responder as tarefas propostas, através de uma filtragem manual. Isto se mostrou necessário para garantir que o resultado não sofresse algum tipo de viés fornecido pelo sistema. Os resultados filtrados serão disponibilizados na tabela comparativa com os resultados encontrados pelos participantes, na seção referente aos registros bibliográficos encontrados. É importante destacar que para a verificação manual, considerou-se a presença dos termos buscados, nos campos: título, autor, resumo, descritor e individuo como tema.

- Apresentação da tarefa aos participantes, que incluiu as etapas de fornecimento de informações sobre o teste ao público selecionado, apresentação da tarefa em um documento impresso e entregue no início da sessão; 
- Realização da tarefa;

- Registro escrito e gravado em áudio, da execução das tarefas;

- Análise dos resultados.

Os participantes foram informados quanto as seguintes questões:

- O propósito da pesquisa;

- O sistema a ser avaliado;

- Porque o participante foi escolhido;

- Como o teste seria conduzido;

- O tempo de duração da avaliação.

Foram mencionadas, aos entrevistados, três questões importantes, antes do início das sessões de avaliação: o fato das sessões serem registradas em áudio; o caráter confidencial das gravações, que seriam utilizadas apenas para fins acadêmicos; e que o teste não seria sobre os usuários e sim sobre o sistema. As sessões tiveram duração de aproximadamente 60 minutos cada.

Os testes foram realizados na sala de trabalho dos bibliotecários, na mesa individual de cada participante, com um computador e acesso à internet. $\mathrm{O}$ áudio foi registrado em um aparelho celular com aplicativo para gravação de áudio, para posterior análise dos comentários dos participantes. $\mathrm{O}$ teste foi conduzido por uma pesquisadora, com esclarecimentos iniciais e orientações acerca das atividades a serem realizadas, na base de dados bibliográfica Base COC. ${ }^{3}$

Ao longo das sessões os usuários foram estimulados a explicar os caminhos que escolheram para a busca pelas informações e a verbalizar os problemas encontrados e as ocorrências, fossem elas de ordem tecnológica ou de alimentação de conteúdo. Foram explicitadas durante a interação: as ações, as dificuldades encontradas, as experiências com a interface e o conhecimento sobre a tarefa. Paralelamente foram conduzidas perguntas de acordo com o desenvolvimento da tarefa.

A utilização de tarefas para busca das informações serviu como condutora das entrevistas e o registro destas tarefas, em termos quantitativos, foi utilizado para verificação do encontro total ou parcial das informações.

\subsection{População e amostra}

Foram selecionados para a pesquisa, bibliotecários, por ser um público especializado no uso de bases de dados bibliográficas e nas técnicas de busca por conteúdo bibliográfico. Como recorte para a pesquisa foram selecionados, dentro da população de bibliotecários, os que atuam na referida biblioteca temática. Os usuários selecionados são representativos de um dos grupos de usuários reais do sistema e utilizam a base de dados, utilizada pela referida biblioteca, constantemente para executar tarefas especificas. Como amostragem, foram entrevistados sete participantes, selecionados com base em duas características de usuários, citadas por Jordan (1998): experiência e domínio do conhecimento.

Experiência - os bibliotecários utilizam a base de dados bibliográfica como instrumento de busca de publicações, para atender as demandas dos usuários da biblioteca e para tratamento da informação sobre o acervo.

Domínio de conhecimento - A familiaridade com o tema da biblioteca e sua base de dados se dá pelo fato dos bibliotecários serem os responsáveis pelo tratamento da informação do acervo inserido no sistema e por

${ }^{3}$ Fonte: Disponível em $<$ http://basecoc.coc.fiocruz.br $>$ 
terem um conhecimento avançado na temática, seja adquirido através de alguma formação acadêmica ou por experiência profissional diária com o acervo.

Os bibliotecários selecionados possuem com relação ao uso do sistema:

- Experiência no uso da base de dados, entre dois e onze anos;

- Acessam o sistema diariamente ou constantemente;

- Fazem uso do sistema como instrumento de trabalho para consulta, catalogação, registro de conteúdo ou auxílio à busca de usuários.

Segundo Nielsen (2000), de acordo com testes de usabilidade conduzidos pelo autor, cinco participantes encontram $85 \%$ dos problemas de usabilidade e depois do quinto participante, os problemas relatados se repetem adicionando menos informações à pesquisa. Neste estudo, no entanto, como a equipe da biblioteca temática é formada por sete profissionais, julgou-se pertinente entrevistar todos os bibliotecários, por serem um público com características específicas.

Os sete participantes se dividiram nos seguintes perfis:

- Cinco participantes do sexo feminino e dois participantes do sexo masculino;

- Os participantes se situaram na faixa entre 31 e 59 anos de idade;

- Seis participantes possuíam graduação na área de biblioteconomia e documentação e um participante era estudante de graduação na área;

- Os participantes tinham experiência na referida biblioteca entre dois e onze anos;

- Um participante era doutorando, dois possuíam mestrado e um possuía MBA;

- Quatro participantes tinham algum tipo de formação acadêmica na área de história das ciências e da saúde.

\section{Resultados}

\subsection{Descrição e avaliação das tarefas}

Os resultados das tarefas foram divididos por quantidade de registros recuperados pelos participantes, como mostrado no quadro abaixo. $\mathrm{O}$ item referente ao resultado da pesquisa prévia diz respeito a quantidade de registros encontrados na fase de preparação da pesquisa, pelos pesquisadores deste estudo, com o uso do formulário de busca simples e com verificação manual, sem filtragem do sistema.

\begin{tabular}{|l|l|l|l|l|}
\hline PARTICIPANTES & TAREFAS & \multicolumn{2}{l|}{ Tarefa 4 } \\
& $\begin{array}{l}\text { Tarefa 1 } \\
\text { Localizar obras do } \\
\text { cientista Carlos } \\
\text { Chagas que fazem } \\
\text { parte do acervo da } \\
\text { Biblioteca }\end{array}$ & $\begin{array}{l}\text { Tarefa 2 } \\
\text { Localizar obras sobre } \\
\text { o cientista Carlos } \\
\text { Chagas que fazem } \\
\text { parte do acervo da } \\
\text { Biblioteca }\end{array}$ & $\begin{array}{l}\text { Tarefa } 3 \\
\text { Localizar obras sobre } \\
\text { Doença de Chagas } \\
\text { que fazem parte do } \\
\text { acervo da Biblioteca } \\
\text { Carlos Chagas à } \\
\text { Doença de Chagas }\end{array}$ \\
\hline Pesquisa prévia & 38 & 94 & 282 & 63 \\
\hline Participante 1 & 79 & 84 & 14 & 8 \\
\hline Participante 2 & 29 & 87 & 267 & 58 \\
\hline Participante 3 & 78 & 86 & 267 & 97 \\
\hline Participante 4 & 78 & 61 & 80 & 104 \\
\hline Participante 5 & 80 & 251 & 267 & 76 \\
\hline Participante 6 & 96 & 76 & 267 & 104 \\
\hline Participante 7 & 80 & 78 & 7 \\
\hline
\end{tabular}

Tabela 1 - Comparação entre o número de registros encontrados na pesquisa prévia e por entrevistado. 
É importante destacar que, na fase de pesquisa prévia, foram recuperados noventa e seis registros sob a autoria de Carlos Chagas. Destes, dez registros diziam respeito a separatas ${ }^{4}$ e foram eliminados do resultado. Entre os oitenta e seis registros restantes, quarenta e oito registros diziam respeito a outros autores, homônimos ou com os termos Carlos e Chagas como partes integrantes do nome, portanto também foram eliminados. Apenas trinta e oito se referiam ao cientista.

\begin{tabular}{|l|l|}
\hline AUTORIA & RESULTADO ENCONTRADO \\
\hline Carlos Chagas (cientista), descobridor da Doença de Chagas & 38 \\
\hline Carlos Chagas Filho $^{5}$ & 17 \\
\hline Carlos Chagas [Filho] $^{5}$ & 28 \\
\hline Carlos Pinheiro Chagas & 1 \\
\hline Carlos Chagas (jornalista) & 2 \\
\hline Outros & 10 \\
\hline Total & 96 \\
\hline
\end{tabular}

Tabela 2- Resultado de busca, encontrados sob o termo "Carlos Chagas".

A seguir seguem as análises realizadas a partir das tarefas propostas:

- Tarefa 1: Localizar obras do cientista Carlos Chagas que fazem parte do acervo da Biblioteca.

Todos os bibliotecários tinham conhecimento da existência de obras do autor Carlos Chagas Filho, no acervo, o que fez com que procurassem verificar se a busca por Carlos Chagas também retornaria este autor, que deveria ser eliminado do resultado. Os cinco participantes com resultados muito próximos entre si excluíram, através do uso de operadores booleanos as obras de autoria do filho do cientista e procederam as outras exclusões através de filtragens manuais. Apenas as obras que foram assinadas como Carlos Chagas Filho foram eliminadas.

Dois participantes obtiveram resultados mais distantes, para mais e para menos, dos outros participantes. O participante 6 utilizou dois campos de busca por filtro autor, um para o nome e outro para o sobrenome do cientista, como método de filtragem. Depois testou a inserção do termo Filho, com o filtro autor no terceiro campo, para verificação (figura 3). Optou pelo resultado, sem a eliminação das obras do filho do autor, por considerar que não foram recuperados na busca por nome e sobrenome separados nos campos. O participante 2 utilizou uma estratégia de busca diferente dos demais e encontrou um resultado aproximado do encontrado na pesquisa prévia. Começou a busca pela exclusão de autores que não fossem o cientista e quando verificou que haveria muitas situações deste tipo, como mostrado nas figuras 4 e 5, estabeleceu o uso do filtro limite de tempo de publicação para fazer um recorte entre 1889 até a data de falecimento do cientista, em 1934 . Relatou que para a busca ser mais precisa quanto ao limite, seria necessário pesquisar a data efetiva em que o cientista começou a publicar livros. O participante entendeu que o período de publicação eliminaria entre outras, as publicações do filho do cientista, que na época ainda não seria um cientista.

\footnotetext{
${ }^{4}$ O Diccionario de la lengua española, da Real Academia Española (1992) define a separata como impressão por separado de um artigo ou capítulo publicado em uma revista ou em um livro. No caso desta pesquisa, os capítulos recuperados não são de autoria de Carlos Chagas, mas pertencem as obras sob sua autoria. Isto interfere no resultado final de obras do cientista, constando uma mesma obra diversas vezes, de forma separada. Fonte: Disponível em $<$ https://dle.rae.es/>. Acesso em: 09 abr. 2020.
}

${ }^{5}$ Carlos Chagas Filho assinava algumas publicações apenas como Carlos Chagas, como o seu pai. Ambos eram cientistas na área de saúde. 


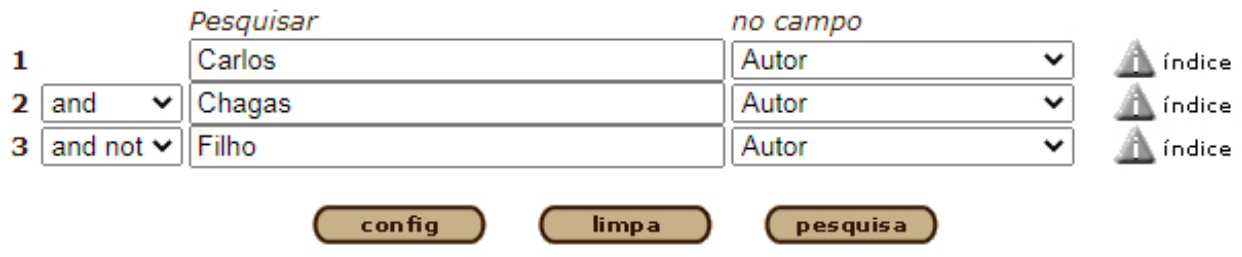

Search engine: $\underline{\text { iAH }}$ v2.6.1 powered by WWWISIS

BIREME/PAHO/WHO - Latin American and Caribbean Center on Health Sciences Information

Figura 3: Extrato do resultado de uma das pesquisas realizadas sobre a autoria de Carlos Chagas, com o preenchimento dos três campos de busca, pelo filtro autor.

\begin{tabular}{|c|c|c|c|}
\hline \multicolumn{2}{|c|}{$1 / 95$} & $\operatorname{coc}$ & $\nabla=$ \\
\hline \multirow{7}{*}{ 聶 } & \multirow{7}{*}{$\begin{array}{l}\text { seleciona } \\
\text { para imprimir }\end{array}$} & & 44191 \\
\hline & & Autor: & : Chagas, Carlos. \\
\hline & & Título: & : Trypanosomiase Americana: synonymia Doença do Barbeiro. \\
\hline & & Fonte: & : São Paulo; s.n; 1918. 33 p. il. \\
\hline & & Resumo(s): & $\begin{array}{l}\text { : Neste artigo Carlos Chagas descreve o transmissor da doença, seu } \\
\text { habitat, forma de ataque aos humanos e a profilaxia }\end{array}$ \\
\hline & & Descritores: & $\begin{array}{l}\text { Doença de Chagas } \\
\text { Triatominae }\end{array}$ \\
\hline & & Localização: & : BR1273.1; F4993 \\
\hline \multirow{8}{*}{\multicolumn{2}{|c|}{$\begin{array}{l}2 / 95 \\
\square \text { seleciona } \\
\text { 鸟 para imprimir }\end{array}$}} & $\operatorname{coc}$ & 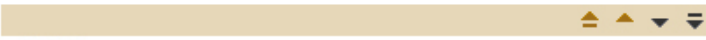 \\
\hline & & & 42708 \\
\hline & & Autor: & : Chagas, Carlos. \\
\hline & & Titulo: & : Cadeira de Medicina Tropical. \\
\hline & & Fonte: & : [Rio de Janeiro]; Typ. do Instituto Oswaldo Cruz; 1926.20 p. . \\
\hline & & Resumo(s): & $\begin{array}{l}\text { : Aula inaugural do Professor Carlos Chagas, no Pavilhão Miguel } \\
\text { Couto, a } 14 \text { de setembro de } 1926\end{array}$ \\
\hline & & Descritores: & $\begin{array}{l}\text { Fala } \\
\text { Escolas Médicas } \\
\text { Medicina Tropical }\end{array}$ \\
\hline & & Localização: & : BR1273.1; F4920 \\
\hline
\end{tabular}

\begin{tabular}{|c|c|c|}
\hline \multirow{6}{*}{$\begin{array}{l}3 / 95 \\
\square \text { seleciona } \\
\text { 舃 para imprim }\end{array}$} & $\operatorname{coc}$ & $\leq \boldsymbol{\Delta}$ \\
\hline & & Id: 42632 \\
\hline & & Autor: Chagas, Carlos. \\
\hline & & $\begin{array}{l}\text { Título: A guerra das estrelas: (1964-1984) os bastidores das } \\
\text { sucessões presidenciais. }\end{array}$ \\
\hline & & Fonte: Porto Alegre; L\&PM Editores; 1985.325 p. . \\
\hline & Res & $\begin{array}{l}\text { umo(s): } 0 \text { autor da obra, jornalista Carlos Chagas, elabora } \\
\text { compilação dos fatos que, a seu ver, foram relevantes em } \\
\text { relação as sucessões presidenciais da Ditadura Militar, além } \\
\text { de relatar acontecimentos por ocasião da tomada do poder, } \\
\text { em } 1964 \text {. A descrição revela-se mais aprofundada em } \\
\text { relação a sucessão do marechal Costa e Silva, primeiro por } \\
\text { uma junta militar e depois pelo general Emílio Médici, } \\
\text { justificando-se tal fato em virtude do autor ser secretário de } \\
\text { imprensa do governo a época. Além disso, o livro contém }\end{array}$ \\
\hline
\end{tabular}

Figura 4: Extrato do resultado de uma das pesquisas realizadas sobre a autoria de Carlos Chagas. Nos dois primeiros resultados figuram obras de autoria do cientista Carlos Chagas e no terceiro, do jornalista de mesmo nome. O campo indicativo de diferenciação se deu pela data da publicação da obra de 1985, no campo fonte, já que o autor procurado faleceu em 1934. 


Id: 95 seleciona 36554
Autor: Chagas, Carlos.
Título: Quelques aspects de l'electrogenese chez l'electrophorus electricus.
Fonte: Rio de Janeiro; Instituto de Biofísica; 1947. 43 p. ^bil.
Resumo(s): L'electrogénèse chez les possons électriques soulève des
problèmes, qui, malgré l'effort de nombreux physiologistes ne sont
pas encore résolus. J'ai trouvé en 1938, auprés du Professeur Alfred
Fessard, à la Foundation Singer Polignac du Collège de France, un
chaleureux accueil qui m'a permis d'entreprendre à mon tour des
recherches sur les poissons électriques du bassin de l'amazone et
celui de l'Orénoque, l'Electrophorus electricus, commuaussi sous le
nom de gymnote ou anguille électrique, dont les résultats sont
présentés dans ce travail. (AU.)
Descritores:
Biologia
Biofísica
Electrophorus
Notas: Pertence à Coleção Carlos Chagas Filho.

Id: 36553
Autor: Chagas, Carlos.
Título: Valor dos estudos de hematologia pathologica.
Fonte: Rio de Janeiro; s.n; 1903. 212 p.
Resumo(s): Tese de doutoramento de Carlos Chagas que discute sobre
assuntos relacionados com o valor dos estudos de hematologia
pathologica para o diagnóstico da Malária. Seu estudo se subdivide
em capítulos: No capítulo primeiro, chamado de hematozoario do
impaludismo, trata-se da unidade e pluralidade do parasita - o typo
febril e o aspecto microscópico do hematozoario - Ensaio de
classificação das fórmulas clinicas do impaludismo observadas nos
hospitais do Rio de Janeiro. No capítulo segundo, chamado de
hematologia do impaludismo, apresenta-se um resumo dos
trabalhos de Vincent, de Türek, de Billet, de Stephens e
Christophers, de Leonard Rogers, de Charles Meland, alguns
estudos originais e a semeiotica da reação hemo-leucocytaria do
impaludismo. No capítulo terceiro, chamado histologia pahologica é
tratado a questão da medula óssea no impaludismo. Conclui-se a
obra com o relato de uma série de observações empíricas sobre o
tema discutido.

Figura 5: Extrato de uma página de resultados. Os resultados 5 e 6 se referem a dois autores diferentes, mas a única indicação se dá pela data de publicação (1947) no campo fonte, como na imagem anterior. Esta obra se refere ao filho do cientista, que em algumas publicações assinava apenas como Carlos Chagas. Além disso, os resumos não são padronizados em idioma e descrição, o que dificulta a filtragem do resultado.

- Tarefa 2: Localizar obras sobre o cientista Carlos Chagas que fazem parte do acervo da Biblioteca. A segunda tarefa teve questionamentos por parte de dois dos bibliotecários, sobre o seu objetivo, o que interferiria na escolha dos filtros. Três bibliotecários consideraram que a pergunta se referia a obras biográficas sobre o cientista. Sendo assim, dois participantes utilizaram o filtro título, por interpretarem que o termo Carlos Chagas deveria estar nele contido e um utilizou o termo biografia como filtro descritor local.

Os outros quatro participantes utilizaram filtros diferentes para cada campo: assunto, indivíduo como tema e palavras. Isto demonstra que a mesma pesquisa pode ser realizada por caminhos diferentes, como mostrado na figura 6, quando se conhece os recursos. As maiores diferenças de resultado se deram nos encontrados pelos participantes 4 e 5 , pela escolha dos filtros. 


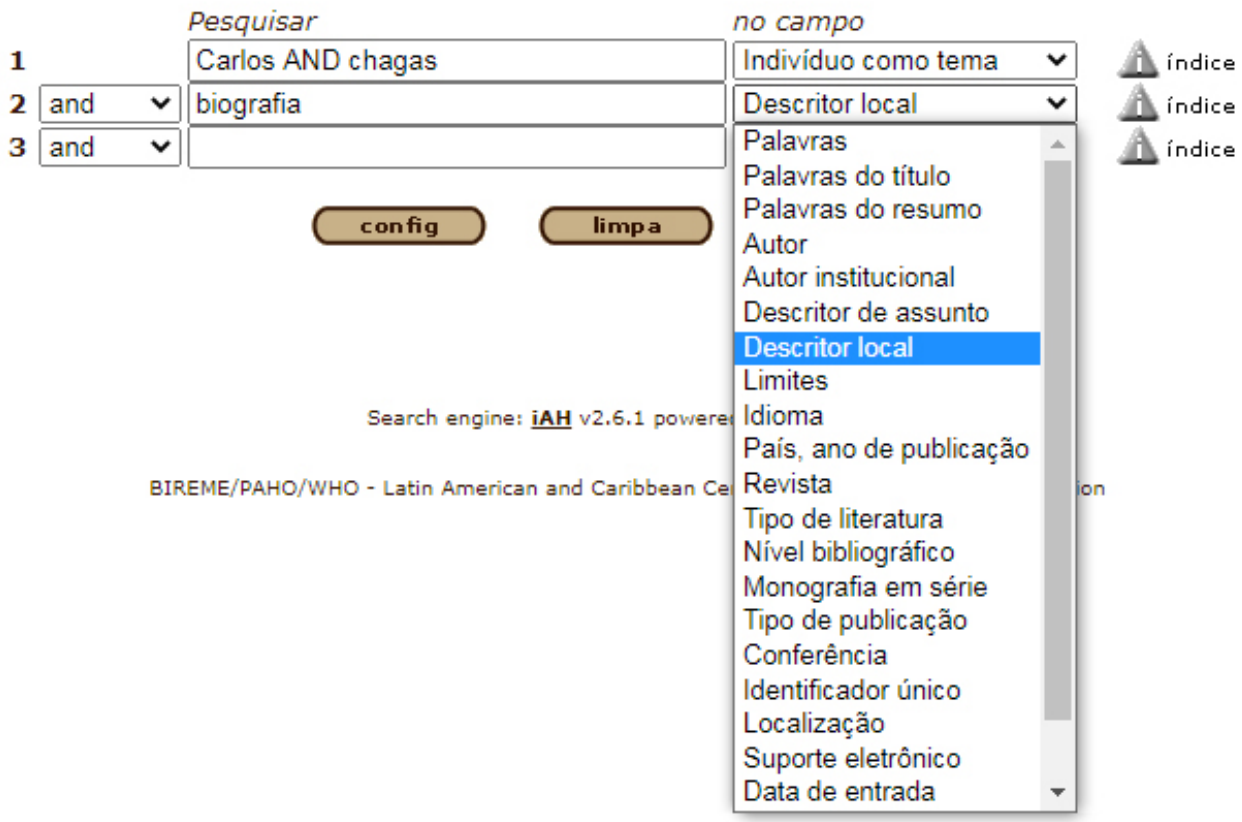

Figura 6: Tela de busca avançada com seleção de filtragem por campos do sistema. Os filtros de busca não deixam claro o seu propósito para usuários não especialistas, pela nomenclatura utilizada, como descritor, descritor local, limite e nível bibliográfico, por exemplo.

- Tarefa 3: Localizar obras sobre Doença de Chagas que fazem parte do acervo da Biblioteca.

A terceira tarefa apresentou em duas das falas dos participantes, que encontraram resultados não aproximados dos demais e da pesquisa prévia, um entendimento sobre uma busca pela doença, com relação ao aspecto histórico.

O participante 1 colocou que a doença de Chagas não tinha esse nome antes de ser descoberta pelo cientista, por isso não buscou por este termo, mas pelo nome científico do causador da enfermidade e o participante 5 fez uma combinação entre Carlos Chagas, como filtro autor e doença como filtro título.

O participante 4 obteve um resultado mais aproximado da pesquisa prévia, separando os termos Carlos e Chagas, ambos com a utilização do filtro palavras. Relatou que este procedimento corresponde a uma busca no formulário simples, sem filtros.

Os outros quatro participantes utilizaram o mesmo filtro, descritor de assunto, e obtiveram resultados iguais.

- Tarefa 4: Localizar obras que relacionam o cientista Carlos Chagas à Doença de Chagas.

A quarta tarefa apresentou o maior nível de diferença entre os resultados encontrados pelos participantes. Pela observação dos procedimentos realizados, verificou-se que ocorreram interpretações diferentes quanto à questão: dois participantes encontraram resultados iguais por utilizarem o mesmo filtro, palavras, por considerarem que a questão se referia a aspectos diversos; dois participantes relacionaram Carlos Chagas como autor e Doença de Chagas como assunto, retornando poucos registros; dois participantes fizeram 
combinações de filtros para os dois termos, que consideraram mais adequados para relacionar o cientista à doença. Nenhum dos participantes fez uma filtragem manual.

\subsection{Análise quanto ao componente de usabilidade - EUP}

Para a análise da EUP, foram considerados dois aspectos: experiência e domínio do conhecimento.

Experiência - os bibliotecários utilizam a base de dados bibliográfica como instrumento de busca de publicações, para atender as demandas dos usuários da biblioteca e para tratamento da informação sobre o acervo. O conhecimento avançado da base de dados se dá também pelo fato dos bibliotecários serem os responsáveis pelo tratamento da informação do acervo inserido no sistema;

Domínio de conhecimento - A familiaridade com a temática da biblioteca, seja adquirido através de alguma formação acadêmica ou por experiência profissional diária com o acervo propriamente dito e sua organização.

A experiência dos bibliotecários foi verificada quanto à linguagem, pois os termos utilizados pertencem à área de biblioteconomia e pela familiaridade com o uso do sistema. Para Jordan (1998), a frequência de utilização do sistema é um dos fatores determinantes para a familiaridade e facilidade de uso. Isto não significa que o sistema seja eficiente, apenas que os usuários se adequaram ao seu uso. Isto foi exemplificado nas falas de dois dos entrevistados:

"Mesmo vindo resultados misturados, o usuário não tem dificuldade. A verificação não é extensa porque os registros aparecem de $20 \mathrm{em} 20$ " [O sistema mostra o resultado da busca dividido em quantas telas forem necessárias, sempre com a visualização de 20 registros por tela]. (Entrevistado 6, usuário da base há 6 anos).

"Os usuários que estão mais acostumados, utilizam com facilidade". (Entrevistado 7, usuário da base há 11 anos)

O domínio de conhecimento do bibliotecário foi verificado de duas formas: quanto a como o sistema foi alimentado, já que os bibliotecários conheciam os filtros possíveis e como o conteúdo foi organizado nos campos do sistema; e quanto ao tema da biblioteca, pois os bibliotecários possuíam formação acadêmica ou experiência no uso do acervo, pelo tempo de prestação de serviço profissional na referida biblioteca.

O conhecimento dos bibliotecários sobre o acervo se mostrou quanto a:

- Conhecimento sobre a organização do acervo no sistema:

O conhecimento dos bibliotecários sobre os termos de indexação, descritores locais e gerais, vocabulário controlado e configuração do acervo facilitou a busca. Isto foi exemplificado no procedimento adotado pelos participantes:

Os entrevistados buscaram Carlos Chagas no campo "descritor de assunto", que é um termo descritor local do acervo da biblioteca, portanto os usuários possuíam um conhecimento prévio sobre os descritores locais do acervo. 


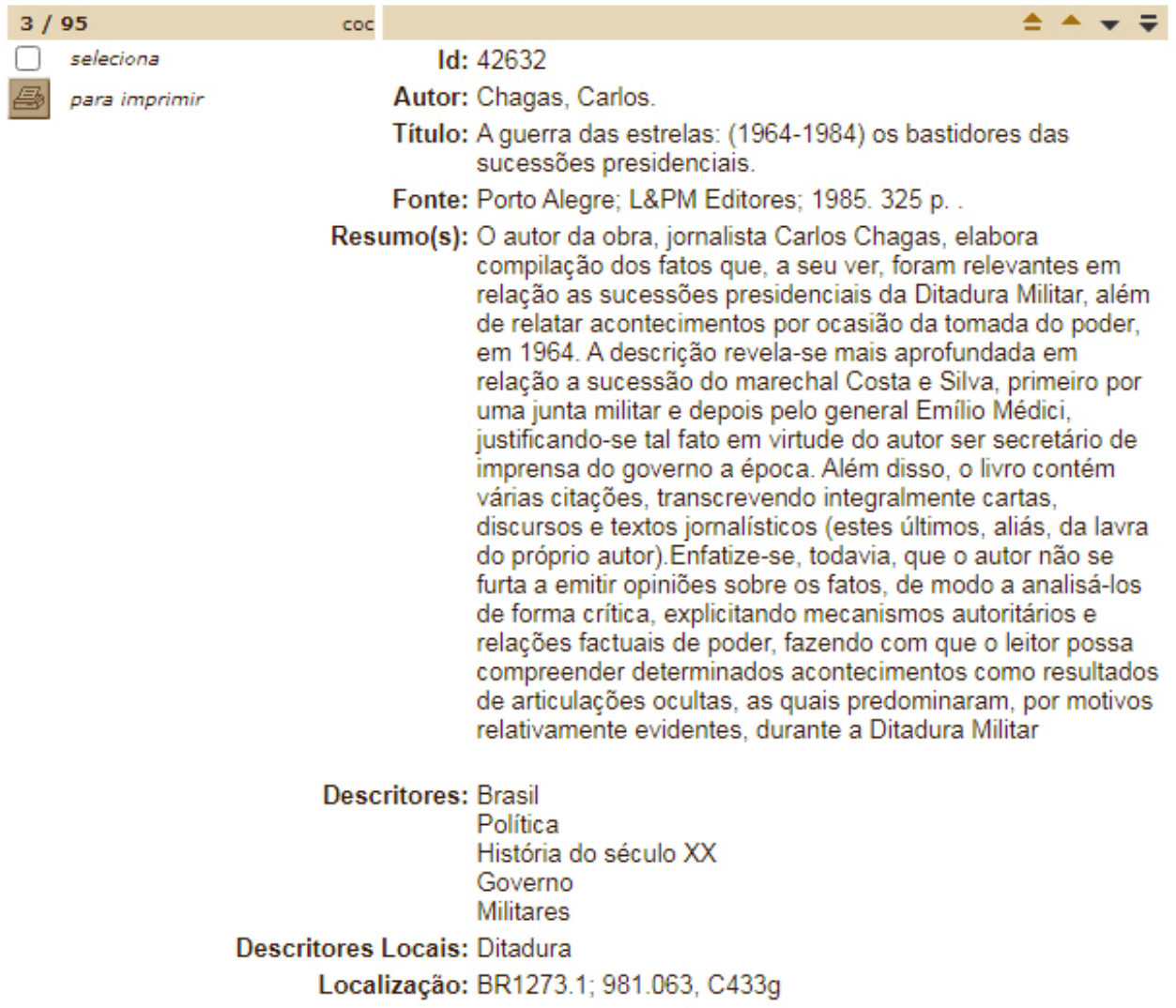

Figura 7: Descrição de um dos registros bibliográficos recuperados. Os campos "descritores" e "descritores locais" não possuem uma diferença clara para um usuário não especializado em termos da área de Biblioteconomia. O campo localização é apresentado por um código, sem a explicação do seu significado.

Um dos entrevistados, na quarta tarefa, considerou o retorno de resultados baixo e refez a busca, por entender que existiam mais registros no acervo, demonstrando que o participante conhecia o acervo da biblioteca. Os entrevistados buscaram por Doença de Chagas, sem o uso do filtro descritor local, pois o termo faz parte do Decs ${ }^{6}$. Os usuários possuíam conhecimento sobre o sistema descritor geral do tema no qual o acervo está inserido.

- Conhecimento sobre a temática do acervo:

A recuperação da informação depende da estratégia de busca adotada, que é facilitada pelo domínio do pesquisador, no caso o bibliotecário, sobre o tema pesquisado. Durante a realização das tarefas, um dos participantes se referiu ao trabalho do bibliotecário especializado em um tema, como uma atividade onde são utilizados critérios de dedução e especulação:

“O bibliotecário é um CSI" [investigador]. (Entrevistado 4, usuário da base há 7 anos)

Um dos entrevistados, ao analisar o resultado fornecido pelo sistema para a primeira tarefa, relatou que um dos registros se referia a uma obra com publicação posterior a data de morte do autor buscado, portanto,

\footnotetext{
${ }^{6}$ Descritores em Ciências da Saúde. Vocabulário controlado de assuntos médicos, com descritores em português, inglês e espanhol, elaborado pela Bireme a partir do Medical Subject Headings (MesH) da National Library of Medicine". (CUNHA, Murilo Bastos da; CAVALCANTI, Cordélia Robalinho de Oliveira. Dicionário de biblioteconomia e arquivologia. Brasília: Briquet de Lemos, 2008. xvi, 451 p. p. 119)
} 
deveria ser eliminada da pesquisa. O entrevistado possuía um conhecimento relativo ao tema, tendo cursos de formação na temática do acervo.

Um dos entrevistados, na terceira tarefa, explicou que a doença de Chagas não tinha esse nome antes de ser descoberta pelo cientista e considerou que seria melhor buscar por um aspecto da doença, como o termo científico do protozoário causador da enfermidade. O bibliotecário demonstrou conhecimento sobre o tema, tendo cursos de formação na temática do acervo.

\subsection{Considerações dos especialistas}

À medida que os usuários realizavam as buscas, foram estimulados a fazer considerações sobre o que impactava na utilização do sistema e como isto poderia ser melhorado. Abaixo são listadas as principais observações feitas pelos bibliotecários, que apresentam uma necessidade de melhoria com respeito a interface e a como implementar uma melhor inserção de dados. Estas observações não foram fatores impeditivos da realização das tarefas propostas, porém foram identificados pelos participantes como questões que impactam na recuperação da informação e no funcionamento do sistema:

- O uso de um campo de busca simples em bibliotecas especializadas não tem sentido, pois recupera registros a partir de todos os campos. Os usuários desses acervos fazem buscas direcionadas e não exploratórias abertas, diferentemente do que acontece em uma biblioteca de temas gerais.

- A catalogação de obras deveria ser o resultado de um trabalho em conjunto entre bibliotecários, especialistas nos temas e usuários que fazem buscas no sistema.

- O campo resumo constante na descrição dos registros, não obedece a uma padronização. Todos os resumos deveriam obedecer a um padrão de descrição mais detalhada das obras. Até mesmo os resumos fornecidos pelos autores deveriam ser construídos sob a ótica da recuperação da informação. Neste sentido, os bibliotecários deveriam assumir um padrão de descrição quando fossem eles ou autores dos resumos, na alimentação do conteúdo ou deveriam manter uma interlocução com os autores, quando esses fornecessem os resumos à biblioteca.

- A recuperação da informação pode ser prejudicada por erros de digitação do alimentador do sistema como a presença de espaços, dois pontos, etc na inserção de dados. Na interface de alimentação (back-end da ferramenta), deveria existir um sistema de prevenção quanto à ocorrência de erros por parte do processo de catalogação. Poderia ser adotado o uso de recursos de autocomplete (preenchimento automático).

- Antes da catalogação, ou seja, do tratamento da informação, a biblioteca deve definir diretrizes, que podem até mesmo ser diferentes das utilizadas de forma geral pela área de biblioteconomia, definindo por exemplo, o uso de apenas uma variação do nome de autor.

- A base deveria ter um catálogo de autoridade ${ }^{7}$, ou seja, uma listagem de autores, o que facilitaria o processo de busca. Alguns autores possuem muitas variações de nome, além da existência de homônimos, o que obriga a conferência no recurso de índice (figura 8), ou conferência manual do resultado. Foi citado que a abrangência do acervo é grande demais para que os bibliotecários conheçam todos os homônimos, o que foi verificado na tarefa 1. Também foi citado que é inviável conhecer todas as obras pelo grande número de autores constantes no acervo e a listagem de autores poderia remeter para as obras individualmente.

\footnotetext{
${ }^{7}$ Listagem formada por nomes de pessoas, entidades coletivas ou eventos associados à autoria de obras e assuntos. Fonte: Disponível em: <https://www.bn.gov.br/explore/catalogos>. Acesso em: 13 jan. 2020. 


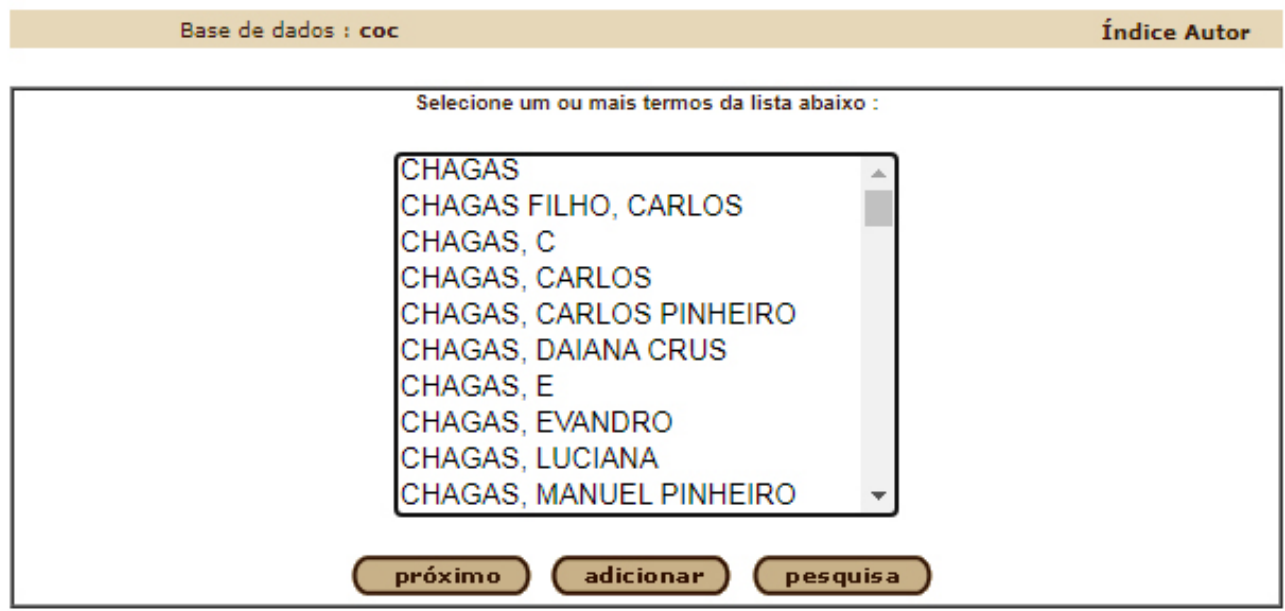

Nova pesquisa no índice

Digite palavra ou início da palavra:

ou selecione a letra inicial

\begin{tabular}{|c|c|c|c|c|c|c|c|c|c|c|c|c|c|c|c|c|c|c|c|c|c|c|}
\hline $012 \ldots$ & A & B & C & D & E & F & G & H & I & J & K & L & M & N & O & P & Q & R \\
\hline S & T & U & V & W & X & Y & Z & & & & & & & & & & \\
\hline
\end{tabular}

Figura 8: Tela da busca por índice dos campos cadastrados. No índice do campo "autor", foram cadastradas três formas variadas referentes ao nome do autor Carlos Chagas (Chagas; Chagas, C; Chagas, Carlos). O comando "adicionar" adiciona o nome selecionado ao campo de busca do formulário avançado na tela de busca prévia, já o comando "pesquisar" direciona para uma página de resultados, não deixando claro como o recurso de índice funciona.

- O sistema fornece apenas três campos de filtros (figura 9), fazendo com que o usuário seja obrigado a incluir dentro dos campos, junto aos termos, combinações com os operados booleanos $A N D, N O T$, $A N D N O T$ e $O R$, o que contraria as recomendações fornecidas pelo sistema. Foi citado por um dos bibliotecários que seria necessário haver um aumento do número de campos para inserção de termos, para filtragem e que a quantidade ideal de campos seria cinco.

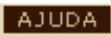

Base de dados : coc

1 Carlos AND chagas

Figura 9: Tela de busca avançada. Não há a possibilidade de adição de mais campos. Os bibliotecários fazem uso de operadores booleanos dentro dos campos de busca, embora não recomendado no texto de notas apresentado na tela inicial do sistema.

- Os bibliotecários não tem dificuldade de entendimento quanto aos termos utilizados, pois são usados na área de biblioteconomia, porém o sistema também é utilizado por não bibliotecários. Os 
participantes relataram que a base deveria falar a língua do usuário, como demonstrado na fala de um dos participantes.

"Nem sempre o consulente sabe a nomenclatura que a gente usa". (Entrevistado 5, usuário da base há 2 anos).

- A denominação "descritor" para um dos campos, foi considerada inadequada e sugerido que o melhor termo seria "assunto".

- O filtro "Identificador único", que se refere a um código atribuído a cada registro, é de uso específico dos bibliotecários e não deveria fazer parte da recuperação para os usuários.

- O filtro número de páginas não oferece nenhuma informação relevante para o usuário, pois não é utilizado para buscas, portanto não seria necessário em uma interface para usuários.

- O filtro "localização" confunde o usuário, pois retorna em forma de código e apenas os bibliotecários entendem que se refere a em que biblioteca, pertencente à rede de bibliotecas da instituição, a obra está localizada. Cada biblioteca é denominada por um código próprio.

"Muitas vezes, o usuário chega aqui apenas com o código de localização, mas isso não diz nada sobre a obra, só em que biblioteca ela está". (Entrevistado 5, usuário da base há 2 anos).

\subsection{Usabilidade da base de dados bibliográfica}

Para condução deste estudo, a eficácia do sistema foi considerada a partir de dois parâmetros: conclusão da tarefa (encontro da quantidade total ou parcial dos itens do acervo) e qualidade da saída (proximidade dos resultados com relação ao número de itens reais do acervo). Todos os participantes concluíram as tarefas propostas, encontrando parcialmente a quantidade de registros apurados na pesquisa prévia. Em alguns momentos houve uma grande diferença entre o número de obras existentes no acervo e o número de registros encontrados pelos bibliotecários, no entanto foi verificado que o trabalho não se esgota de forma simples, pois diversas estratégias de busca e filtragem dos resultados são adotadas. É necessário tempo para verificação dos resultados, pois eles só são realmente considerados como finais após uma verificação item a item. Verificou-se que dois fatores afetaram a qualidade da saída: a estratégia de busca adotada e o entendimento quanto as tarefas propostas.

Quanto à eficiência do sistema, três fatores demonstraram a demanda por um maior esforço para realização das tarefas: a filtragem de resultados, a necessidade de consulta ao acervo físico e a necessidade do uso de sistemas de auxílio externo. A filtragem automática possui questões quanto aos filtros autor e resumo, exigindo uma filtragem manual dos resultados. Além disso, durante a condução das tarefas, se mostraram evidentes que os resultados encontrados pelos participantes eram preliminares e que as pesquisas demandariam um tempo maior do que o proposto para o teste, como consequência pelo sistema não fornecer respostas precisas de forma automática, o que ocasionava a necessidade de uma filtragem manual dos resultados. O segundo fator se refere a necessidade de conferência das obras no acervo físico, para dirimir questionamentos que o sistema não consegue responder. O terceiro fator que impacta a pesquisa em tempo e esforço cognitivo é a necessidade do uso de sistemas externos, como auxílio à tarefa de busca. Isto pode ser caracterizado como um desvio do caminho crítico, pois o sistema deveria ser capaz de responder as questões colocadas pelos bibliotecários durante o processo de busca. De acordo com Jordan (1998), a maior parte das tarefas pode ser realizada por um caminho crítico, que exige o menor esforço do usuário e a necessidade de uso de ajudas online são exemplos de desvios desse caminho, porque impactam a eficiência em termos de tempo gasto e quantidade de esforço do usuário. Na base de dados estudada, a eficiência do sistema poderia ser melhorada a partir de implementações simples.

Apesar do sistema informar que não deveriam ser utilizados operadores booleanos entre as palavras no campo de busca, o fornecimento de apenas três campos para preenchimento, no formulário avançado, fez com que os bibliotecários contrariassem as recomendações, para realização das buscas. Isto vai ao encontro

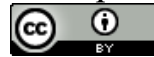


do que já foi citado anteriormente por Cybis, Betiol e Faust (2010) de que o usuário ao entender novas funcionalidades e possibilidades, desenvolvem estratégias próprias. O conhecimento dos especialistas difere dos usuários, e também entre si, pois nem todos os participantes usaram o mesmo procedimento. Alguns seguiram estritamente o que foi colocado pelo sistema. Os bibliotecários consideraram que a estratégia vai sendo construída à medida que a pesquisa avança e que deve se tentar cercar a pesquisa pelo maior número de ângulos possíveis. Preferem procurar o máximo de recuperação para depois refinar os resultados gradativamente, pois algumas ocorrências indesejáveis aparecem ao longo do caminho, não podendo ser previstas. A estratégia de busca é um processo complexo que se inicia a partir do questionamento feito pelo usuário, com uma filtragem mental prévia e que depois é aplicada ao sistema. Um dos participantes colocou que os usuários tem dificuldades na construção da estratégia, por não saberem formular as perguntas adequadas:

"O usuário tem dificuldades em construir as perguntas, por isso o bibliotecário tem que refazê-las ou auxiliar o usuário nessa tarefa. O Google é igual vó, acostumou a gente muito mal”. (Entrevistado 4, usuário da base há 7 anos)

A experiência e o domínio do conhecimento dos participantes tiveram impacto sob o processo de busca e consequente resposta do sistema. Isto foi demonstrado nas tarefas 1 e 2 , onde a mesma pesquisa pode ser realizada por caminhos diferentes e o conhecimento dos bibliotecários proporcionou um entendimento sobre como traçar estratégias e reencaminhá-las, quando necessário em bases de dados. As tarefas 1 e 3 demonstraram que o conhecimento avançado sobre o tema pode auxiliar a construção de estratégias de busca no sistema e permite entender o contexto que cerca o que está sendo buscado, como por exemplo, o conhecimento de questões relativas à doença, que foi tema da tarefa 3 , por exemplo. Já o conhecimento do vocabulário especializado, dos campos de descrição demonstrou que eles possuíam domínio sobre como operar os filtros e técnicas de busca mais adequadas.

\section{Conclusão}

As tarefas propostas serviram de guia para a condução das entrevistas e se mostraram importantes por revelar as estratégias de busca adotadas pelos participantes e como a experiência e domínio do conhecimento tem influência sobre a operação de busca e encontro de resultados pela base de dados bibliográfica. Como os bibliotecários entrevistados são também os alimentadores de conteúdo, eles possuem uma visão privilegiada do sistema, o que trouxe para a pesquisa questões que foram relatadas durante o teste, pois impactavam no mesmo, embora não fizessem parte das tarefas em si.

Baseado nas observações feitas durante a realização das tarefas, pode-se concluir que a experiência dos bibliotecários no uso do sistema e o conhecimento sobre o acervo e o tema do acervo afetam a facilidade em concluir a tarefa e que a estratégia de busca é subjetiva, não sendo formulada previamente, pois depende do andamento da recuperação de resultados e é criada a partir de perguntas, que dependem do conhecimento da organização dos dados no sistema, do conhecimento sobre o tema e do domínio da ferramenta. Esta constatação é particularmente importante, visto que a base de dados não é de uso exclusivo dos bibliotecários, tendo como foco principal o acesso as publicações por usuários interessados em história das ciências e da saúde, não necessariamente especialistas no tema ou usuários avançados no uso da base de dados. É importante levar em conta que o conhecimento avançado dos bibliotecários facilita a utilização do sistema, pois a facilidade de uso se refere a uma soma entre interface, características dos usuários, objetivo e situação de uso, como colocado por Cybis, Betiol e Faust (2010) e Jordan (1998). Esse entendimento do impacto das características do usuário pode auxiliar a entender em que medida o sistema deve ser concebido, assumindo-se que os usuários não especialistas não possuem o mesmo domínio de conhecimento e a falta deste não pode ser uma barreira ou limitação para o encontro da informação. A base de dados bibliográfica, após a realização desta pesquisa, entrou em processo de desativação, ainda não concluído até a finalização deste artigo. A Biblioteca em História das Ciências e da Saúde, por uma determinação da instituição, irá 
utilizar uma única base de dados entre as bibliotecas pertencentes à Fundação Oswaldo Cruz, visando uma melhor integração entre os acervos bibliográficos da instituição. Este trabalho, embora tenha sido realizado com base em uma ferramenta específica traz considerações que podem ser passíveis de aplicação em outras bases de dados bibliográficas, pela semelhança entre as mesmas.

\section{Referências bibliográficas}

CICCARELLI, L. D.; GRANJA, A. F.; RENZI, A. B. Avaliação cooperativa para identificar interação de aplicativos com interfaces de voz no aprendizado de idiomas. $4^{\circ}$ Simpósio de Pós-Graduação em Design da Escola Superior em Desenho Industrial, 2018.

CYBIS, W.; BETIOL, A. H.; FAUST, R. Ergonomia e usabilidade: Conhecimentos, Métodos e Aplicações. 2. ed. São Paulo: Novatec Editora, 2010.

DUARTE, E. J.; VIEIRA, F. S.; SILVEIRA, J.; LOPES, A. F. Os serviços e os produtos de informação oferecidos pela Biblioteca Pública de Santa Catarina, in: Revista ACB: Biblioteconomia em Santa Catarina, Santa Catarina, v. 20, p. 606-620, 2015.

JORDAN, Patrick. An introduction to usability. London: Taylor \& Francis, 1998.

MELCHER, Christiane. Proposta metodológica para avaliações otimizadas de usabilidade de websites desenvolvidos com método ágil: um estudo de caso. Dissertação (Mestrado em design). Pontificia Universidade Católica do Rio de Janeiro. Rio de janeiro, 2012.

MESQUITA, R. M. A.; BRAMBILLA, S. D. S.; LAIPELT, R. do C. F.; MAIA, M de F. S.; VANZ, S. A. de S.; CAREGNATO, S. E. Satisfação de usuários no uso de base de dados bibliográfica: em estudo de caso. VI Encontro Nacional de Pesquisa em Ciência da Informação, 2005.

NIELSEN, Jakob. Usability 101: Introduction to usability. 2003. Disponível em: $<$ https://tfa.stanford.edu/download/IntroToUsability.pdf>. Acesso em: 17 nov.2019.

NIELSEN, Jakob. Why You Only Need to Test with 5 Users. 2000. Disponível em: $<$ https://www.nngroup.com/articles/why-you-only-need-to-test-with-5-users/>. Acesso em: 14 jan.2020.

SANTA ROSA, J. G.; MORAES, A. de. Avaliação e projeto no design de interfaces. 2. ed. rev. e ampl. Teresópolis: 2AB, 2012.

VEIGA, V. S. de O.; PIMENTA, D. N.; MACHADO, R.; SILVA, A. da; SILVA, C. H. da; Repositórios institucionais: avaliação da usabilidade na Fundação Oswaldo Cruz. XIV Encontro Nacional de Pesquisa em Ciência da Informação, v.14, 2013.

\section{Agradecimentos}

Agradecemos aos bibliotecários participantes desta pesquisa, pela disponibilização de tempo e apoio para a realização das entrevistas. Ao Professor Sydney Freitas pelo apoio na definição do método utilizado. À Biblioteca em História das Ciências e da Saúde e à Casa de Oswaldo Cruz/ Fiocruz, que contribuíram para a viabilização deste estudo. Ao Programa de Pós-Graduação em Design da Esdi/Uerj. 